\title{
Ações de Docência com Uso de Tecnologias Digitais na Formação Inicial de Professores de Matemática
}

\section{Teaching Actions Using Digital Technologies in the Initial Training of Mathematics Teachers}

\author{
Ivanete Fátima Blauth*a; Suely Scherer ${ }^{\mathrm{a}}$
}

\begin{abstract}
aUniversidade Federal de Mato Grosso do Sul, Programa de Pós-Graduação Stricto Sensu em Educação Matemática. MS, Brasil.
*E-mail: ivanetefatima@hotmail.com.
\end{abstract}

\begin{abstract}
Resumo
Neste artigo discutimos resultados de uma pesquisa em que se analisou ações propostas em uma disciplina de Prática de Ensino, identificando aquelas que podem ter possibilitado a construção de conhecimentos tecnológicos e pedagógicos de conteúdo, por egressos de um curso de Licenciatura em Matemática. Dentre as ações identificadas, duas são relacionadas à aprendizagem da docência, uma vivenciada na sala de aula da disciplina, em que o acadêmico teve colegas como alunos, e a outra realizada no espaço da escola, em que o acadêmico assumiu a regência de uma aula de matemática em escolas de Educação Básica. O objetivo neste artigo é analisar essas duas ações e possíveis relações com a construção de conhecimentos tecnológicos e pedagógicos de conteúdo matemático. Os dados foram produzidos na pesquisa a partir de entrevistas realizadas com 27 egressos desse curso de Licenciatura em Matemática, que realizaram a disciplina de Prática de Ensino e concluíram o curso, no período de 2010 a 2015. A partir da análise de "falas de egressos", concluiu-se que as duas ações propostas na disciplina de Prática de Ensino, nas quais os professores em formação tiveram a oportunidade de praticar a docência, podem ter oportunizado a construção de conhecimentos tecnológicos e pedagógicos de conteúdo matemático. Nessas ações, esses egressos tiveram que estudar conteúdos matemáticos e tecnologias, de maneira a atender objetivos de aulas e favorecer a aprendizagem de seus alunos.
\end{abstract}

Palavras-chave: Prática de Ensino. Formação Inicial. Matemática. Tecnologias Digitais.

\begin{abstract}
In this paper we discuss the results of a research in which actions proposed in a Teaching Practice discipline were analyzed, identifying those may have made the construction of technological and pedagogical knowledge, by graduates of a Mathematics Degree. Among the actions identified, two are related to teaching learning, and other experienced in the classroom, in which the students was the academic's colleagues, and the other was in the school space, in which the academic took over the conduct of a class of mathematics in Basic Education schools. The objective of this article is to analyze these two actions and possible relationships with the construction of technological and pedagogical knowledge of Mathematical content. The data were produced in the research based on interviews with 27 graduates of this Mathematics Degree, who took the Teaching Practice discipline and completed the course, from 2010 to 2015. From the analysis of the "speeches of graduates", it was concluded that the two actions proposed in the Teaching Practice discipline, in which the teachers in training had the opportunity to practice teaching, may have given rise to the construction of technological and pedagogical knowledge of Mathematical content. In these actions, these graduates had to study Mathematical content and technologies, in order to meet class objectives and favor the learning of their students.
\end{abstract}

Keywords: Teaching Practice. Initial Formation. Mathematics. Digital Technologies.

\section{Introdução}

No contexto em que vivemos, onde as tecnologias digitais fazem parte do cotidiano de muitas pessoas, podemos realizar várias atividades a partir de aparelhos conectados à internet, como fazer compras sem sair de casa, conversar com pessoas de diferentes localidades, e até mesmo criar canais para comunicação ou para divulgar desde receitas de bolo, até trabalhos científicos. Da mesma forma, muitas crianças e adolescentes, por vezes caracterizados como "nativos digitais" $"$, possuem diferentes habilidades com tecnologias digitais, por crescerem em espaços com acesso a tecnologias, em especial, celulares.
De acordo com pesquisa de Orlando \& Attard (2016), alguns nativos digitais estão iniciando suas atividades como docentes, porém, o que se observa em muitas escolas, é que mesmo com possíveis professores "nativos digitais", as tecnologias digitais se fazem pouco presentes nas atividades de ensino e de aprendizagem. Fato esse que nos preocupa como professoras e pesquisadoras, e tem nos mobilizado a investigar usos de tecnologias digitais na escola, na sala de aula, na formação de professores. Afinal, se tecnologias digitais estão inseridas no cotidiano de alunos e professores, se em muitas escolas há tecnologias como computadores e lousa digital, por que nos cursos e ações de formação de professores, pouco se integra tais tecnologias ao currículo, aos

1 Pessoas que nasceram no período em que as tecnologias digitais começaram a ser conectadas à internet e que as informações estão mais acessíveis e rápidas (Prenski, 2001). 
processos de ensino e de aprendizagem?

Neste contexto, foi realizada a pesquisa de mestrado de Blauth (2017), que neste artigo discutimos alguns resultados. Esta pesquisa teve por objetivo analisar ações propostas em uma disciplina de Prática de Ensino, identificando aquelas que podem ter possibilitado a construção de conhecimentos tecnológicos e pedagógicos de conteúdos matemáticos, por egressos de um curso de Licenciatura em Matemática, de uma universidade pública de Mato Grosso do Sul. Os dados da pesquisa foram produzidos a partir de entrevistas realizadas com 27 egressos desse curso de Licenciatura, concluintes no período de 2010 a 2015, que fizeram uma disciplina de Prática de Ensino com foco no estudo/uso de tecnologias digitais.

A partir das falas dos egressos nas entrevistas, foram realizadas análises orientadas por estudos sobre a construção de conhecimentos de Becker (2012), e estudos realizados por Mishra \& Koehler (2006) sobre os conhecimentos Tecnológico, Pedagógico, de Conteúdo, e suas inter-relações.

Blauth (2017) identificou três ações que podem ter mobilizado a construção de conhecimentos tecnológicos e pedagógicos de conteúdo por egressos do curso: elaboração de planejamento de aulas com tecnologias digitais, desenvolvimento de aulas com o uso de tecnologias digitais, e a metodologia da disciplina pautada na relação teoria-prática. Dentre essas ações, duas estão relacionadas diretamente à aprendizagem da docência: a primeira foi vivenciada na sala de aula da disciplina, em que cada acadêmico teve colegas como alunos, e a segunda foi realizada no espaço de escolas de Educação Básica, em que cada acadêmico assumiu a regência de uma aula de matemática. Neste artigo, o objetivo é analisar essas duas ações e possíveis relações com a construção de conhecimentos tecnológicos e pedagógicos de conteúdo, a partir do ponto de vista dos egressos.

Nas próximas seções apresentamos o referencial teórico sobre conhecimentos e ações de docência para o uso de tecnologias digitais, os procedimentos metodológicos da pesquisa, e a análise de algumas falas de entrevistados relacionadas às duas ações mencionadas anteriormente, além de tecer algumas considerações a partir da pesquisa realizada.

\section{Conhecimentos e Ações de Docência para o Uso de Tecnologias Digitais: Alguns Elementos Teóricos da Pesquisa}

Segundo Gatti (2013), o objetivo das licenciaturas é formar profissionais para o trabalho docente na Educação Básica, no entanto, o que é oferecido, na maioria dos cursos, pode ser considerado um "verniz superficial" em relação aos fundamentos que são importantes ao futuro professor. Isto posto, nos mobilizamos a investigar uma proposta de curso de formação inicial de professores de matemática, principalmente a formação com/para o uso de tecnologias digitais. Acabamos por investigar a proposta de uma disciplina de Prática de Ensino, ao analisar falas de egressos de um curso de Licenciatura em Matemática desta universidade, que mencionaram diferentes ações propostas durante essa disciplina. Ações essas, que eles consideraram importantes para a sua formação e atuação em sala de aula, por terem vivenciado a docência com o uso de tecnologias digitais.

Essas ações de formação podem resultar em conhecimento sobre a docência, pois segundo Becker (2012), o "conhecimento é sempre resultado de uma construção" (p. 188), que depende de ações do sujeito. Ou seja, durante as ações desenvolvidas, cada professor em formação constrói para si um conhecimento, que pode ser (re)construído de acordo com necessidades e oportunidades. Sobre a possibilidade de construir conhecimentos para a docência, durante sua formação inicial, podendo vivenciar algumas situações práticas, Carneiro (2008, p.59) afirmou que:

Os cursos de formação devem proporcionar situações que aproximem a realidade da sala de aula, criando simulações, de modo que os futuros professores tenham contato com características próprias da primeira - incerteza, complexidade, singularidade -, sem a responsabilidade da prática na qual suas ações são irreversíveis.

Nesse sentido, nos cursos de formação inicial de professores seria importante investir em ações como a simulação de aulas (que nesta pesquisa consideramos ser o desenvolvimento de aulas em que os colegas de turma são "os alunos"), que se aproximam da realidade da sala de aula nas escolas. São ações em que os professores em formação são desafiados a representar/vivenciar situações que podem ocorrer em sala de aula da Educação Básica, no caso desta pesquisa, quando fazem uso de tecnologias digitais.

Para Marcon, Graça \& Nascimento (2010, p.13), durante as interações estudante-estudante ou estudante-professor, os conhecimentos podem ser produzidos, principalmente se na formação inicial estes estudantes tiverem a oportunidade de "se defrontar com diferentes dilemas e situações problemas, fundamentalmente em contextos reais de ensino e aprendizagem".

Pensando no processo de formação quando se faz uso de tecnologias digitais, Almeida (2000, p.171) considera que os futuros professores, além de conhecerem tecnologias, precisariam "vivenciar situações em que atue com outra pessoa e com o grupo, ora como observador ora como mediador da exploração do computador". Para mobilizar esse processo, a autora considera importante que o ciclo descrição-execuçãoreflexão-depuração, seja a "mola mestra" em todas as ações de formação. Esse ciclo acontece quando:

O professor toma consciência de sua prática, levanta e testa hipóteses sobre sua ação (executa-as através do computador ou sem a presença do mesmo), reflete em sua ação e sobre sua ação pedagógica, analisa a adequação de suas intervenções e, finalmente, depura sua atuação para torná-la mais apropriada ao desenvolvimento de seus alunos. (Almeida, 2000, p. 45)

Esse ciclo de ações descrição-execução-reflexãodepuração-descrição também foi proposto e estudado por Valente (2005), no qual se considera que a construção do 
conhecimento acontece na ação, na interação do aprendiz com o computador. Almeida (2000, p.172) afirma que o ciclo pode mobilizar a construção de conhecimentos durante a formação:

Quando é promovida a atuação do formando como mediador do uso do computador com outros alunos, o ciclo é empregado para incitar à reflexão sobre como o aluno aprende e como ocorre a mediação. Isso propicia a depuração da atuação e cria um processo contínuo de revisão e transformação da prática pedagógica.

Neste sentido, podemos pensar que o professor em formação, ao vivenciar a ação da docência com o uso de tecnologias digitais, tem a oportunidade de vivenciar o ciclo, reelaborando-o, de acordo com as situações propostas e necessidades. Ou seja, uma das possibilidades para que o ciclo possa ser vivenciado, é quando o formador propõe ações, que façam com que os futuros professores vivenciem, durante a formação inicial, momentos para elaborar/executar/discutir/ refletir sobre conteúdos, metodologias, recursos, avaliação, e sobre situações que ocorreram em alguma sala de aula. Essas ações podem potencializar a construção de conhecimentos importantes para o exercício da docência.

Ao dialogar sobre conhecimentos para a docência, precisamos dialogar sobre o uso de tecnologias digitais. Mishra \& Koehler (2005) usam o termo TPACK (Technological Pedagogical Content Knowledge), que traduzimos para português como o Conhecimento Tecnológico e Pedagógico do Conteúdo (CTPC), para discutir sobre conhecimentos do professor para a docência com uso de tecnologias. Para esses autores, há conhecimentos importantes para que os professores possam integrar as tecnologias em suas práticas pedagógicas, pois consideram que

apenas a introdução de tecnologia no processo educativo não é o suficiente para garantir a sua integração, e que a tecnologia por si só não leva à mudança. [...] é a maneira que os professores usam a tecnologia que tem o potencial para mudar a educação. (Koehler \& Mishra, 2005, p. 132, tradução nossa)

Nos estudos sobre conhecimentos do professor para a docência com tecnologias, Mishra \& Koehler (2006) introduziram o conhecimento tecnológico (CT) aos estudos sobre tipos de conhecimento do professor, realizados por Shulmann (1986). Dentre os conhecimentos estudados por Shulmann, destacamos o conhecimento pedagógico (CP), o conhecimento de conteúdo (CC), o conhecimento curricular, e a inter-relação entre esses conhecimentos (CC e CP), o conhecimento pedagógico de conteúdo.

Para Mishra \& Koehler (2006) há três tipos de conhecimentos necessários ao professor, o conhecimento pedagógico, o conhecimento de conteúdo e o conhecimento tecnológico, além dos conhecimentos oriundos das interrelações entre eles. O conhecimento pedagógico $(\mathrm{CP})$ é um profundo conhecimento sobre as metodologias e métodos de ensino, processos de aprendizagem, objetivos, valores educacionais, gerenciamento de plano de aulas, quem são os alunos, .... O conhecimento de conteúdo (CC) é o conhecimento sobre o conteúdo específico, conteúdo matemático, no caso de nossa pesquisa, que precisa ser ensinado ou aprendido. E o conhecimento tecnológico (CT) envolve o conhecimento de habilidades necessárias para operar determinadas tecnologias, independente de elas serem digitais; é um conhecimento que precisa se modificar constantemente, uma vez que as tecnologias evoluem.

Os conhecimentos oriundos das inter-relações desses três conhecimentos são o conhecimento pedagógico de conteúdo, conhecimento pedagógico tecnológico, o conhecimento tecnológico de conteúdo, e o conhecimento tecnológico pedagógico de conteúdo. O conhecimento pedagógico de conteúdo (CPC) (já discutido por Shulmann), é o conhecimento necessário aos professores para propor o ensino de determinado conteúdo curricular por meio de práticas pedagógicas que favoreçam a compreensão dos alunos. O conhecimento pedagógico tecnológico (CPT) é o conhecimento sobre a existência de diferentes tecnologias, e como elas podem ser usadas em contextos de ensino e de aprendizagem; é o conhecimento de como o ensino pode ser transformado a partir do uso de tecnologias. O conhecimento tecnológico de conteúdo (CTC) é o conhecimento necessário para escolher a tecnologia que melhor se adapta ao conteúdo que se deseja ensinar. De acordo com Koehler et al. (2013), o CTC é um conhecimento sobre como determinados conteúdos podem ser representados a partir do uso de tecnologias digitais.

O conhecimento tecnológico pedagógico de conteúdo (CTPC) é um conhecimento que representa a inter-relação entre os três conhecimentos (pedagógico, tecnológico e de conteúdo); é o conhecimento do uso de tecnologias para ensinar e aprender um conteúdo específico, ou seja, um conhecimento necessário para o professor que utiliza tecnologias em suas aulas. No caso da pesquisa desenvolvida, CTPC é o conhecimento do professor sobre o conteúdo matemático que deseja ensinar e como ensiná-lo (processos, estratégias de ensino) utilizando-se de tecnologias.

Diante do exposto, e por compreendermos que as ações de docência vivenciadas durante a disciplina de Prática de Ensino investigada envolviam o estudo/uso de tecnologias digitais, os conhecimentos discutidos nas pesquisas de Mishra \& Koehler orientaram a análise dos dados. Para melhor compreensão da análise realizada, na próxima seção apresentamos os procedimentos metodológicos da pesquisa.

\section{Material e Métodos}

A pesquisa foi desenvolvida com a participação de 27 egressos de um curso de Licenciatura em Matemática, de uma universidade pública do Mato Grosso do Sul, que tem em sua matriz curricular uma disciplina de Prática de Ensino, cuja ementa prevê o estudo sobre usos de tecnologias digitais (softwares e applets) em/para aulas de Matemática da Educação Básica. Optamos por investigar conhecimentos produzidos nesta disciplina, ao tomarmos conhecimento de sua proposta no grupo de pesquisa GETECMAT (Grupo de 
estudos de tecnologia e educação matemática), do qual somos membros, pois era diferenciada, e tínhamos interesse em investigar ações da formação de professores com o uso de tecnologias digitais.

Essa disciplina de Prática de Ensino geralmente é oferecida no $5^{\circ}$ semestre letivo do curso, tem carga horária de 68 horas, e sua ementa se constitui das seguintes temáticas: tecnologias digitais e aprendizagem na escola, análises e integração ao currículo escolar de applets e softwares voltados ao ensino de Matemática, planejamento de aulas para ambientes informatizados.

Para iniciar a pesquisa, foi realizado um estudo minucioso do referencial teórico, que em parte, apresentamos neste artigo, do projeto pedagógico do curso, e dos planos de ensino da disciplina ofertada nos anos de 2010 a 2015. A partir desse estudo, foi elaborado um roteiro para uma entrevista semiestruturada, a ser realizada com egressos que realizaram a disciplina, e concluíram o curso no período de 2010 a 2015. A escolha desses egressos foi em decorrência da professora da disciplina de Prática de Ensino, no período selecionado, ter assumido uma metodologia de trabalho focada na docência dos acadêmicos, com o uso de tecnologias digitais.

A opção por analisar "falas de egressos" foi por considerarmos que estes poderiam estar atuando em sala de aula, como professores de matemática, e por isso, poderiam, ao falar sobre a sua formação inicial, em especial sobre a proposta da disciplina de Prática de Ensino investigada, expressar conhecimentos que foram construídos e foram significativos para sua atuação profissional.

No período de 2010 a 2015, segundo dados obtidos com a secretaria acadêmica do curso da universidade, se formaram 49 professores de Matemática. Assim, para a realização das entrevistas, foram enviados convites, por e-mail, aos 49 egressos, e recebemos resposta positiva de 27 deles. Eles são os participantes da pesquisa, e para a análise dos dados, os identificamos por P1 (professor 1), P2, P3, ..., P27. Algumas entrevistas foram realizadas presencialmente, em diferentes locais a partir da sugestão dos egressos, outra via Skype.

Os dados da pesquisa se constituíram a partir das entrevistas, e de um questionário aplicado a todos os participantes no dia da realização da entrevista. O questionário foi elaborado para obter algumas informações sobre o professor. As entrevistas foram gravadas e transcritas. A análise e interpretação dos dados foi realizada a partir das falas dos participantes da pesquisa, e articuladas com o referencial teórico, com foco em analisar ações propostas na disciplina de Prática de Ensino, identificando aquelas que podem ter possibilitado a construção de conhecimentos tecnológicos e pedagógicos de conteúdos matemáticos por egressos de um curso de Licenciatura em Matemática. Vale lembrar que "as falas" representam o que o professor falou no momento da entrevista, e que não foram realizados contatos posteriores com os participantes, durante a análise, para obter mais informações sobre o que eles falaram. Dessa forma, nem sempre foi possível identificar o conteúdo matemático, as tecnologias (softwares ou applets) utilizadas pelo professor, e nem como foram utilizadas por eles.

A partir das leituras e releituras das entrevistas transcritas, identificamos nas falas dos participantes, três ações da disciplina que podem ter mobilizado a construção de conhecimentos tecnológicos e pedagógicos de conteúdo: elaboração de planejamento de aulas com tecnologias digitais, desenvolvimento de aulas com o uso de tecnologias digitais, e a metodologia da disciplina pautada na relação teoria-prática. Neste artigo, analisamos duas ações, que estão relacionadas à aprendizagem da docência: a primeira vivenciada na sala de aula da disciplina, em que o acadêmico teve colegas como alunos; e a segunda, que foi realizada no espaço da escola, em que o acadêmico assumiu a regência de uma aula de matemática em escolas de Educação Básica. O objetivo aqui é analisar essas duas ações e possíveis relações com a construção de conhecimentos tecnológicos e pedagógicos de conteúdo.

\section{Resultados e Discussão}

\subsection{Prática da docência com uso de tecnologias digitais: reproduzindo a sala de aula de Matemática, tendo colegas de curso como alunos}

Identificamos e analisamos falas de professores em que se referem a ação da disciplina relacionada ao desenvolvimento de aulas, sendo os colegas de turma, os "seus alunos". Um dos pontos que os egressos comentaram na entrevista, e que em parte apresentamos a seguir, é que a metodologia utilizada na disciplina oportunizava a vivência de situações que se aproximavam da realidade do professor de matemática, em especial, ao ser proposto o desenvolvimento de aulas planejadas, simulando uma aula com turmas da Educação Básica, tendo por alunos os colegas da disciplina. Ao participar dessa ação, temos indícios de que os professores em formação tiveram a oportunidade de realizar práticas "em ambientes que tentam reproduzir a realidade da sala de aula, podendo cometer erros e, com isso, identificá-los, avaliá-los e refletir sobre eles para que não aconteçam quando estiver diante de alunos reais" (Carneiro, 2008, p.59).

Sobre essa ação proposta na disciplina de Prática de Ensino, destacamos a seguir algumas falas dos entrevistados:

P2: eu gostei muito da disciplina que a gente teve de tecnologia porque foi lá que eu consegui vivenciar essa questão de aprender com o computador, a gente elaborava aula e aplicava com os colegas, a gente vivenciou tanto, como posso dizer, vivenciou o lado do professor, de lidar com as diferentes perguntas dos alunos, cada um com seu computador, cada um com um processo de aprendizagem diferente, a gente vivenciou isso, mas também esse processo de aprender por meio do computador, de desenvolver atividades usando tecnologia, então eu gostei muito.

P14: A gente teve que fazer planejamento em cima do software escolhido, [...] tinha que dar aula pra sala, trabalhava em grupo, geralmente trio ou dupla, e a gente fazia uma aula pra apresentar pra nossa sala mesmo.

P22: Na disciplina de Prática de Ensino, a gente tinha que 
aplicar um trabalho, [...], tinha aula de softwares e a gente tinha que fazer um trabalho, tinha que preparar uma aula pra nós, como se fosse pro ensino fundamental ou ensino médio, a gente preparava essa aula e apresentava para os alunos e para a professora da disciplina de prática.

Nestas falas, podemos observar, em especial nos nossos grifos, que os professores entrevistados falaram sobre o desenvolvimento de aulas em que assumiram o papel de professores na disciplina de Prática de Ensino. Eles comentaram sobre a metodologia das aulas, de como a trabalharam em grupos na elaboração e desenvolvimento de aulas planejadas. P2 em sua fala deu indícios de que essa ação na disciplina foi uma oportunidade de construir conhecimentos sobre a docência, em especial sobre o processo de aprendizagem dos alunos, quando se faz uso de tecnologias. Ele destacou ainda, que essa disciplina de Prática de Ensino proporcionou ações para que eles pudessem vivenciar o papel do professor, aprendendo a se situar diante de perguntas e desafios que podem surgir durante a sua vida profissional, e que tiveram a oportunidade de aprender matemática usando o computador, no papel de alunos, quando outros colegas assumiam o papel de professor.

P14 e P22 reafirmaram a importância das ações de docência que realizaram na disciplina, nas quais podiam desenvolver uma aula para/com os colegas, tendo oportunidade de ensinar e aprender com o uso de algum software. P22 falou sobre elaborar uma aula "como se fosse para o ensino fundamental ou médio", o que nos remete a pensar que essa ação pode ter mobilizado a construção de conhecimentos para a docência na Educação Básica.

Cada professor entrevistado expressou à sua maneira os conhecimentos mobilizados, o que podemos entender que representa a forma particular, única, que cada ser humano tem em construir e externalizar seus conhecimentos. Durante a entrevista, cada professor, de acordo com as vivências dele nessa disciplina, expressava algumas particularidades que foram significativas para ele. Nesse sentido, resgatamos a fala de P1, em que ele comentou sobre essa ação proposta na disciplina.

P1: dá uma experiência, te coloca em situações em que você tem que fazer isso, tem que utilizar [as tecnologias]. Nós tivemos uma aula onde nós buscamos um software ou applet, depois a partir do software a gente dava uma aula sobre algum conteúdo de matemática. Então basicamente além de ter um applet, tem que pensar em um conteúdo [...] além de apresentar vários caminhos ela [se referindo à disciplina] faz você pensar em como utilizar, em que pode utilizar e já tentar selecionar qual software ou applet é possível relacionar a determinados conteúdos.

P1 nessa fala comentou sobre ações da disciplina que podem ter favorecido a construção de conhecimentos. Desde selecionar um software e utilizá-lo (conhecimento tecnológico), pensar em um conteúdo que pode ser explorado no software (conhecimento tecnológico do conteúdo), pensar em como usar um software na aula (conhecimento pedagógico da tecnologia), até "a partir do software dar uma aula sobre algum conteúdo de matemática", que envolve a mobilização e a construção de conhecimento tecnológico e pedagógico do conteúdo matemático (CTPC).

Entendemos que para desenvolver uma aula usando tecnologias é difícil mobilizar apenas o conhecimento tecnológico, por exemplo. São as inter-relações entre conhecimentos (CC, CP e CT) que potencializam as práticas pedagógicas com o uso de tais tecnologias. Essas ações de formação voltadas à aprendizagem da docência podem ter mobilizado um ciclo ou vários ciclos de ações na construção de conhecimento, uma vez que eram realizadas em interação com o computador, com os colegas e professora. Além disso, essas ações possibilitavam a reflexão e a depuração de estratégias utilizadas nas/para as aulas.

Nas falas de P11 e P25 também foram identificados indícios de construção do conhecimento CTPC, ao comentarem sobre a metodologia das aulas da disciplina, e a oportunidade de aprender por meio de situações que podem também acontecer em sala de aula.

P11: a sala era dividida em grupos, cada grupo ficava com um applet e a gente tinha que a partir do applet, ver que conteúdo que a gente poderia trabalhar com ele e apresentar uma aula pra sala. Então era como se o grupo fosse o professor e a sala fossem os alunos, então eu lembro até, é realmente engraçada a situação, porque a nossa professora ela, às vezes a gente ficava acanhado de fazer alguma coisa, pra tentar não prejudicar o grupo, com tal coisa que, como era a turma de colegas a gente não queria forçar, ou fazer alguma coisa, daí a professora fazia assim, ela levantava a mão, e começava a perguntar assim: Professor, e fazia uma situação que poderia acontecer na sala, pra ver como que a gente se virava, e era com essas situações que a gente ia aprendendo, como que poderia acontecer na sala de aula.

P25: a gente fazia planejamento, fazia alguma pesquisa sobre atividades que dava pra fazer e apresentava em sala de aula. Como se eu fosse professor de uma classe de matemática, ensinando um conteúdo e o software era um suporte pra ensinar aquele conteúdo, ou para realizar uma atividade. No caso do GeoGebra ele era interessante para as duas coisas, tanto pra fazer uma atividade, quanto pra ensinar um conteúdo novo de uma maneira mais conceitual, mais prática.

P11 e P25 falaram sobre as ações da prática da docência, de como aconteciam as aulas que simulavam com a turma de colegas que realizava a disciplina, em que agiam como se eles fossem os professores da turma. P25 falou sobre potencialidades do software GeoGebra ${ }^{2}$, além disso, falou da necessidade de planejamento para que ações de docência pudessem ser desenvolvidas. Podemos considerar, a partir da fala desse egresso e da proposta da disciplina, que para desenvolver aulas com o uso de um software como o GeoGebra,

\footnotetext{
2 Um software que pode ser utilizado durante as aulas de Matemática como recurso didático para estudar vários conteúdos, podendo ser adaptado aos objetivos de aula de cada professor. Há versão online, e aplicativo de celular (alguns já com visualização de realidade aumentada). < https://www. geogebra.org/download?lang=pt $>$.
} 
por exemplo, é importante que os professores elaborem um planejamento das ações de aula, pensando nos objetivos, no conteúdo a ser desenvolvido, nas potencialidades e limitações em relação ao software e ao contexto, e em como possibilitar que os alunos aprendam a partir do uso de tal software. A partir dessa fala, temos indícios de que esse professor pode ter construído CTPC durante o planejamento de aula, e também ao desenvolver a aula, uma vez que pôde agir e interagir com os colegas e com o computador, dialogar, conversar, refletir... e a partir dessa ação, (re)construir seus conhecimentos sobre/ para a docência.

P11 falou sobre uma limitação do seu grupo em relação às aulas com os colegas, pois por ser aula com a turma (seus colegas), eles não queriam prejudicá-los (consideravam que suas perguntas poderiam prejudicar a aula do colega, ao invés de potencializar aprendizagens sobre a docência). Por isso, pensavam e propunham atividades ou situações que fossem mais tranquilas de serem resolvidas. Mas a professora da disciplina, ao perguntar, desafiava-os para irem além do planejamento, para que pudessem pensar sobre a atividade na turma, e compreender que na sala de aula, com os alunos, outras situações poderiam emergir. Tal atitude nos dá indícios de que a professora da disciplina propunha "novas questões ou paradoxos que desestabilizassem as afirmações inadequadas e mobilizassem a construção de novos conhecimentos." (Almeida, 2000, p. 175)

Ainda podemos considerar que a professora, atenta aos movimentos da aula, observou que a turma de acadêmicos podia estar sendo poupada de possíveis problemas que poderiam surgir na sala de aula da Educação Básica, e assim, previa diferentes situações que poderiam/podem acontecer em sala de aula, e intervinha para que os professores em formação (seus alunos), pudessem fazer reflexões sobre a docência. Isso está de acordo com Almeida (2000), que considera que "cabe ao professor provocar reflexões sobre os diferentes estilos usados pelos alunos" (p.44). Essa atitude da professora pode ter sido mais uma oportunidade de construção de conhecimentos sobre a docência, considerando o que emerge em aulas de matemática com uso de tecnologias na escola, e que exigem flexibilidade e conhecimentos dos professores, para reelaborarem seus planejamentos, na/durante as aulas.

Sobre a maneira como os professores construíam conhecimentos para a docência durante esta disciplina, destacamos a fala de mais dois professores:

P20: Cada grupo pegou um aplicativo diferente e quando a gente ia fazer atividades pra eles, a gente ia percebendo que eles também tinham dificuldades. Eu conhecia o software, mas os meus colegas não sabiam, então ia vendo as dificuldades que eles tinham ali, pra trabalhar aquele software e assim acontece com os meus alunos também. Então já ia pensando o que poderia encontrar de dificuldade em sala de aula, como se fosse trabalhar aquele software, aquele conteúdo com os alunos.

P3: nós nos organizamos e tivemos que pegar os conteúdos que se encaixassem naquele software, estudar o software [...] quando a gente estudou, não foi só apresentado, a gente teve que estudar como mexer, pra que serve, porque além da gente aprender, também tinha que ensinar para os outros colegas. Porque eles não estudaram, meu grupo estudou esse software, a gente tinha que saber o suficiente pra ensinar para os colegas, tanto como desenvolvia, como aprender a mexer, então isso ficou gravado. Foi muito legal. Eu aprendi bastante.

P20 comentou que durante o desenvolvimento das aulas, em que assumiu o papel do professor, ele pode identificar dificuldades dos colegas no momento em que estes realizavam as atividades propostas com o uso do software. Tal afirmação denota a importância dos conhecimentos tecnológicos do professor, para que possa auxiliar seus alunos nos momentos de dificuldades, reconstruindo assim seus conhecimentos pedagógicos da tecnologia na prática.

Esse professor, ao identificar dificuldades durante a atividade com os colegas, também podia pensar em estratégias e metodologias para propor a atividade matemática em outras aulas, com aquele software, por exemplo, e minimizar as dificuldades de seus alunos, que poderiam surgir durante as aulas. Portanto, P20 parece ter mobilizado CTPC de matemática, e teve a oportunidade de durante essa pratica de docência, em sua formação inicial, refletir sobre algumas situações, para repensar suas futuras práticas com o uso de tal software.

$\mathrm{Na}$ fala de P3 também podemos identificar indícios de CTPC, pois ele relatou que para ter condições de exercer a docência, eles tinham que estudar para conhecer sobre o software e sobre o conteúdo. Assim, nessa ação de planejamento tinham a oportunidade de construir esses conhecimentos, pois planejavam atividades com o uso do software, para favorecer a aprendizagem de conteúdos matemáticos. Afinal, cada grupo estudava um software para explorar um conteúdo matemático, depois vivenciava a docência, simulando uma aula, tendo os colegas como alunos, e avaliava com todos, potencialidades e limitações de cada software para aprender o conteúdo matemático.

Sobre os conhecimentos construídos nessa disciplina, a necessidade de continuar pesquisando e estudando para o desenvolvimento das aulas com tecnologias, resgatamos as falas de P12 e P20:

P12: foi discutido, trabalhado na formação inicial, depois que você terminou aquela disciplina, terminou o curso, tem que buscar mais, buscar se atualizar, se formar, estudar, pesquisar outros softwares e tal, pra melhorar sua prática pedagógica, pro seu currículo [...] acredito que tem que buscar mesmo, porque aquilo era uma base inicial, é como diz que na graduação é formação inicial, e que pra mim teve muita importância.

P20: essa foi uma disciplina que a gente trabalhou bastante as tecnologias, e a gente viu que tem muita coisa que pode ser usada em sala de aula, na escola. E cada vez aparecem mais novidades, então tem que estar sempre se atualizando, não ficar só no que a gente viu na graduação, tem que procurar estar sempre participando, procurando, pesquisando pra se atualizar, porque esse mundo digital evolui muito rápido.

Nestas falas podemos observar que na disciplina havia discussões sobre a necessidade do professor, mesmo após 
terminar a formação inicial, estar em constante movimento de (re)construção de seus conhecimentos, mobilizando um ciclo ascendente de aprendizagem. Ascendente, porque não consideramos o conhecimento do professor como algo acabado e pronto, mas que a partir do que já vivenciou e experienciou, a partir de suas ações, sempre poderá obter informações novas para a (re)construção de conhecimentos. Ou seja, a docência exige do professor um constante pensar e repensar de práticas pedagógicas a partir de diferentes e novas demandas que surgem a partir da evolução da humanidade, da ciência e da tecnologia. Nesse sentido, a discussão sobre a necessidade de formação continuada é pertinente à formação inicial de professores, uma vez que "toda formação é sempre provisória numa sociedade que não permanece estática, mas se transforma pela atuação do homem e pela evolução do conhecimento" (Nogueira, 2013, p. 310).

Por fim, podemos considerar que a ação de aula simulada, além de possibilitar discussões teóricas e práticas pode ter favorecido a construção de CTPC. Os indícios dessa consideração estão nas falas de alguns professores, quando relataram que ao assumir o papel de professores, puderam planejar, experienciar e avaliar o uso de tecnologias digitais em aulas de matemática, dialogando e refletindo sobre o "próprio processo de aprendizagem, o papel do professor." (Almeida, 2000, p.171)

Falando sobre conhecimentos, cuja construção pode ter partido da disciplina, resgatamos a fala de P8:

P8: cada grupo tem a missão de promover um estudo a partir de um determinado conteúdo matemático, com um determinado software que era possível, teve grupo discutindo o Cabri Geometrics, pra discutir, pra gente estudar, [...] a gente tinha essa missão de pensar em uma proposta nos moldes teóricos que a gente estava estudando, e apresentar isso pro público [a turma da disciplina]. A prova disso é que a gente saiu com essa bagagem de conhecimentos que eu tenho, porque eu conheço essas propostas e elas podem ser readaptadas conforme, e isso de certo modo me inspira a fazer coisas com aquilo sabe, por mais que eu tenho que adaptar, eu posso fazer uma coisa parecida com tal assunto, com tal software, por isso eu acho que isso foi daquela disciplina, trazer a inspiração pra essas práticas, pra minha prática, inspiração pra minha prática.

Nesta fala podemos observar que $\mathrm{P} 8$ se refere à disciplina como inspiração para suas práticas pedagógicas, que as ações desenvolvidas nesta disciplina mobilizaram a construção de conhecimentos relacionados a aulas de matemática com uso de softwares. Na fala de P8 podemos identificar conhecimentos pedagógicos da tecnologia, pois o professor afirmou que a partir de conhecimentos construídos na disciplina, pode "readaptá-los" em suas aulas, tentando fazer algo, no mínimo, parecido com o que foi aprendido. Nesta fala, o professor dá indícios de que pode reconstruir conhecimentos toda vez que irá "adaptar" práticas com o uso de softwares às suas aulas, práticas essas que foram aprendidas na disciplina.

P26 também falou sobre a ação da docência junto aos colegas da turma:
P26: Nessa disciplina eu gostei da maneira que foi trabalhado, todos os grupos fizeram, todos os grupos percorreram essas ideias, todos tiveram um momento de preparar uma aula, aplicar uma aula com a tecnologia. Deu pra ver as dificuldades que os próprios colegas de curso tinham, apareceu dificuldade de software, dificuldade na atividade, dificuldade de postura, as vezes a gente queria fazer aquela coisa, mas acabava passando uma resposta, então essa disciplina acho que foi muito legal por causa disso, essa ideia de conduzir, a postura teórica dos alunos, como que é a ideia de aula que a gente pode fazer lá. Eu achei legal essa disciplina por causa disso, e aí ficou muito parecida com o que você enfrenta em sala de aula que é a ideia que eu falo de você estar vivenciando em sala de aula.

Nesta fala, o professor P26 faz uma análise do que representou para ele vivenciar a regência, usando tecnologias. Ele fala sobre dificuldades que foram surgindo na turma, dificuldades essas que surgem ao agir, ao praticar a docência, e aprender fazendo uso de tecnologias digitais. P26 ainda comentou que esta ação da disciplina oportunizou vivenciar momentos muito parecidos com o que se enfrenta no dia a dia da profissão docente.

A partir das análises aqui apresentadas, podemos observar que os professores entrevistados falaram sobre o desenvolvimento de aulas em que assumiram o papel de professores na situação em que simulavam a docência, e agiram como se fossem os professores de seus colegas de turma. $\mathrm{Na}$ fala da maioria dos professores, podemos identificar que essa ação da disciplina pode ter oportunizado a construção de conhecimentos sobre a docência, pois durante a disciplina, puderam vivenciar o papel de professor que faz uso de tecnologias. Ao assumir esse papel, eles precisaram agir, elaborando planejamentos de aula, estudando aplicativos e softwares, e escolhendo/estudando conteúdos matemáticos que pudessem ser explorados a partir de determinada tecnologia. Na regência tiveram a oportunidade de aprender a avaliar o processo de aprendizagem de cada colega, agir a partir de perguntas e desafios lançados pelos alunos (colegas e professora de turma), e refletir sobre situações que podem acontecer no cotidiano da profissão, em sala de aula.

Nessa prática da docência, mencionada por alguns professores entrevistados, podemos identificar a possibilidade de construção de diferentes conhecimentos, mas principalmente de CTPC. Eles relataram que não apenas conheceram tecnologias, mas que tiveram oportunidade de aprender a usá-las para planejar e desenvolver aulas de matemática na Educação Básica. Ao vivenciarem a docência com o uso de tecnologias, foi possível explorar conhecimentos matemáticos, identificar possíveis dificuldades que poderão surgir em aulas, avaliar possíveis mudanças do planejamento a partir de novas situações que surgiram em aula, e discutir com os colegas e professora da disciplina potencialidades e limitações das tecnologias utilizadas. 


\subsection{Prática da docência com uso de tecnologias digitais: assumindo a regência em aulas de Matemática da Educação Básica}

As análises apresentadas nesta sessão serão apresentadas a partir de falas de professores que mencionaram a ação proposta na disciplina de Prática de Ensino, em que eles realizaram uma prática de docência em escolas de Educação Básica, durante aulas de Matemática.

Vale lembrar que essa ação não foi o único contato que esses professores tiveram com alunos nas escolas no período da realização da atividade, a maioria dos alunos estava realizando estágios obrigatórios nas escolas, previstos no curso. Por esse motivo, acreditamos que essa ação vivenciada na disciplina foi uma oportunidade para o acadêmico "recontextualizar o que foi aprendido e a experiência vivida durante a formação para a sua realidade da sala de aula." (Valente, 2003, p. 3)

$\mathrm{Na}$ fala de P18 identificamos alguns procedimentos dessa ação na disciplina, e que segundo ele, são um diferencial para quem quer utilizar tecnologias em aulas.

P18: Depois no final da disciplina, a gente tinha que trabalhar com alunos, ir à uma escola. Nos grupos foi discutido para trabalhar com esses alunos utilizando um aplicativo. Então esse como que vai fazer, com qual conteúdo, como que você vai fazer aquilo e até o dia que chega na aula, os alunos estão com dificuldade. $\mathrm{E}$ aí a gente teve que na hora ver uma forma pra eles entenderem, então teve esse contato, além de ser apresentada aquela ferramenta a gente teve que estar trabalhando com ela já na disciplina com os alunos, e aí foi legal porque estimula mais, porque não é só a nota, que você vai ter que trabalhar também, tem grande potencial nas aulas de matemática.

P18 se referiu a esta ação da disciplina como algo de grande potencial, pois os incentivou a agirem e desenvolverem aulas com alunos das escolas. Desta forma, podemos pensar que as ações de discutir e pensar durante a elaboração do planejamento, em como fazer as atividades, qual conteúdo e qual tecnologia seria utilizada, possibilitou ao P18 a construção de conhecimentos sobre a docência com uso de tecnologias.

Ao vivenciar os desafios de assumir a função de professor de Matemática, ainda durante o curso de formação inicial, principalmente ter esse contato com alunos da Educação Básica em sala de aula, esse professor pode construir esses conhecimentos. Essa ação pode ter possibilitado um olhar mais atento para as discussões sobre o uso das tecnologias digitais em aulas de matemática, uma vez que estas, já estão inseridas no contexto da maioria das pessoas, e também nas escolas, podendo ser utilizadas como recurso para favorecer a aprendizagem dos alunos.

Essa prática na disciplina também foi comentada por P11. Ele falou em especial sobre o conteúdo matemático que trabalhou em sala de aula com os alunos.

P11: Na disciplina de Prática de Ensino, que a gente começou a usar applets e softwares, a gente fez muito planejamento de aula, a gente aplicou aula em sala de aula, foi nas escolas [...] A gente teve um trabalho, a gente teve que fazer uma aula, usando um aplicativo, eu lembro que o meu grupo ficou com o GeoGebra, a gente usou o GeoGebra pra ensinar o plano cartesiano, para os alunos do $9^{\circ}$ ano, pra eles conhecerem o plano cartesiano, saber que ele é infinito pra um lado, infinito pro outro, saberem como que é a marcação de um ponto, como que a gente denota, o que é o eixo das ordenadas, das abscissas, foi uma atividade prática que a gente fez. Os alunos conseguiram aprender e a gente conseguiu ter um bom resultado [...] uma coisa que me ajudou muito nessa questão da Prática de Ensino, que é quando a gente aprende a pensar como que o aluno aprende a partir de um software, ou a partir de um applet. Então isso foi de muito proveito pra mim [...] nessa prática de tecnologias a gente estudou, a gente saiu de lá e é como se a gente tivesse saído pronto pra aplicar aquilo em sala de aula. A gente sabe como tem que aplicar aquilo.

P11 comentou sobre a aprendizagem deles como professores. Além disso, reforçou a ideia de que nessa disciplina ele teve a oportunidade de vivenciar o contato com alunos da Educação Básica, e aprender a pensar sobre como o aluno aprende quando se faz uso de tecnologias digitais em aulas de matemática. Pela fala de P11, foi importante a oportunidade de vivenciar as aulas na escola e de aprender fazendo uso das tecnologias, pois ele diz se sentir preparado para trabalhar com as tecnologias em outras oportunidades.

P18 e P23 também comentaram sobre os desafios que enfrentaram ao vivenciar a prática com alunos nas escolas. Eles falaram sobre as contribuições dessa disciplina para a construção de conhecimentos e sobre como superar desafios e desenvolver aulas com o uso de tecnologias digitais nas escolas. Vejamos as falas desses professores:

P18: Foi um primeiro contato com os alunos, um pouco de experiência, um pouco de conhecimento ali pra estar lidando com os alunos, às vezes surgia alguma dificuldade na hora de estar lidando com aquilo [...] eu me identifiquei mais com a prática por causa da questão dessa dificuldade que eu tinha, um pouco assim, medo de dar aula. Parece que me ajudou mais por estar tratando disso, como eu poderia pensar conteúdo que às vezes a gente está com dificuldade, como eu poderia ter uma nova abordagem [...] acho que isso me ajudou mais, a parte de ser professor.

P23: Pra ir pra sala de aula, o professor falou mais ou menos o que ele queria, o que ele estava trabalhando, era uma turma do $6^{\circ}$ ano, e era fração e aí a gente conversou com a professora e tudo, e achou melhor pegar um applet porque não teria todo aquele problema de instalar software, computador bloqueado e não sei o que, e isso e aquilo. Todos aqueles probleminhas, a gente não teria com um applet, da internet. Mas assim sempre tinha conteúdo, tinha que pensar em software pra aquele conteúdo sendo sempre meio que determinado.

P18 falou de um desafio pessoal, que precisou ser superado para poder vivenciar essa prática, pois para ele, essa prática foi seu primeiro contato com alunos. Esse professor precisava superar o medo de ministrar aulas. Segundo ele, a disciplina além de propor esse primeiro contato com alunos, também oportunizou discussões teóricas e metodológicas que o auxiliaram "a encarar" a sala de aula e vivenciar a docência, possibilitando-lhe momentos de construção de conhecimentos pedagógicos para a docência, com uso de tecnologias.

P23 comentou que o professor da escola foi quem 
determinou o conteúdo que ele queria que fosse trabalhado com os alunos. A partir desse conteúdo (frações para uma turma de $6^{\circ}$ ano), eles tiveram que decidir qual seria a tecnologia digital a ser utilizada para explorar o conteúdo e atender aos objetivos de aprendizagem da aula a ser realizada. P23 ainda comentou que conversaram com a professora da disciplina antes de escolherem o applet (que poderia ser acessado com uso de internet, e não precisaria ser instalado no computador). Tal fato denota que nessa ação proposta na disciplina, em que acadêmicos atuam como professores na escola, a orientação contínua da professora contribuiu para a formação deles.

Essa ação proposta na disciplina de Prática de Ensino dá indícios de que os professores podem construir conhecimento sobre a vida profissional, no espaço da escola, desde que as escolas abram espaço para receber acadêmicos. Ao falarem dessa prática na escola, os entrevistados comentaram sobre conhecimentos relacionados às limitações da gestão da escola, em relação à infraestrutura disponibilizada, reorganização de planejamentos para poder alcançar os objetivos da aula, o tempo de aula, dificuldades dos alunos, dentre outros desafios próprios da vida do professor nas escolas.

Podemos inferir que essa ação da disciplina possibilitou a esses egressos (re)construção de conhecimentos sobre o conteúdo (tiveram que estudar o conteúdo a ser trabalhado), sobre tecnologias (conhecer potencialidades de softwares e applets e saber decidir qual o melhor para aquela aula), e sobre a pedagogia (decidir sobre estratégias e métodos a serem utilizadas durante a aula, e as reconstruir na prática e na avaliação sobre a prática). Ou seja, os acadêmicos tiveram a oportunidade de construir CTPC. Sobre essa oportunidade P24 comentou que a disciplina era:

P24: mais pra gente aprender a trabalhar com esses softwares, aprender a trabalhar com os nossos alunos, porque esse era o principal, o objetivo da disciplina, que a prática de ensino é ensinar você como professor, práticas de ensino melhores pra trabalhar com os alunos, práticas de ensino como você vai trabalhar com seus alunos, pra que o aluno aprenda melhor, a parte pedagógica.

Nessa fala de P24, podemos observar a importância destacada por ele, de aprender a utilizar o computador, conhecer os softwares e, ao mesmo tempo, poder pensar em estratégias de uso do computador para utilizá-lo em sala de aula com os alunos. Identificamos também na fala de P24, a possibilidade de construir o conhecimento tecnológico pedagógico nesta ação que, segundo Mishra e Koehler (2006, p.1028), representa o "conhecimento de estratégias pedagógicas para o uso de tecnologias". Este é um conhecimento importante para pensar em práticas pedagógicas que favoreçam a aprendizagem dos alunos com tecnologias, o que inclui saber escolher as tecnologias para cada aula e objetivo.

Alguns entrevistados comentaram sobre a avaliação que era realizada após o desenvolvimento de atividades na escola. Vejamos o comentário de P8:

P8: Nessa disciplina a gente teve que aplicar, a gente desenvolveu uma aula, sabe que não sei bem certo, uma aula, a gente desenvolveu uma sequência de atividades que foi corrigida, testada, apresentada, e como o trabalho foi na aula, você tinha que fazer alguma avaliação. Em seguida a gente foi em sala, teve que aplicar isso em sala, e trazer as nossas observações dessa proposta, o que tinha, o que deu errado, o que deu certo, o que mudaria, o que não mudaria, e essas coisas assim, de colocar em prática aquilo que a gente tinha pensado em sala, também foi bem legal.

P8 falou da ação desenvolvida na escola, que durante essa prática poderiam fazer observações e anotações sobre tudo o que acontecia, para avaliar e discutir na disciplina a aula desenvolvida, e repensá-la. Esses momentos de avaliação de aulas na disciplina podem ser importantes para a reflexão e (re)construção de conhecimentos sobre a docência com uso de tecnologias, pois esses professores ao "se envolverem com o processo reflexivo desencadeado durante o curso, descobrem equívocos sobre sua própria prática pedagógica e começam a vislumbrar possibilidades de modificá-la" (Almeida, 2000, p. 118).

Os professores, nesta ação da docência na escola, ao utilizarem o computador e outras tecnologias digitais para favorecer a aprendizagem de seus alunos, precisaram refletir ao planejar a aula (antes), ao desenvolver as atividades (durante), e ao avaliar a aula (após). P20 falou da reflexão após o desenvolvimento da aula:

P20: Cada grupo levava as suas dificuldades, como foi que ele trabalhou aquele software. É mais interessante, ficou muito mais interessante do que se fosse só o professor explicando e passando tudo, só ele pegar e falar pra gente fazer, a gente colocando a mão na massa fica muito mais interessante.

Para P20 essa ação de vivenciar a docência na escola e depois poder discutir as dificuldades enfrentadas e a forma como foi trabalhada a aula possibilitou uma experiência "mais interessante". Ao agir durante a aula desenvolvida na escola, e em seguida poder discutir as dificuldades que surgiram, esses professores estavam aprendendo a lidar com as situações de sala de aula, colocando em prática alguns dos conhecimentos que são necessários para a profissão docente.

Pelas falas dos professores que citaram essa ação de vivenciar a docência em sala de aula com alunos, podemos concluir que eles avaliam como importante a ação proposta na disciplina de Prática de Ensino. E, consideramos que essa ação é uma possibilidade de construir CTPC, pois para desenvolver essa aula com os alunos, os professores precisaram pensar em conteúdo matemático, escolher a tecnologia que melhor atendia os objetivos da aula, em uma metodologia que pudesse favorecer a aprendizagem de seus alunos, a construção de conhecimentos matemáticos.

A partir das falas dos egressos aqui apresentadas, podemos considerar que a professora da disciplina teve fundamental importância nesse processo de construção de conhecimentos. $\mathrm{Na}$ atividade com o uso de tecnologias digitais em que os acadêmicos deveriam simular aulas com os colegas, e na atividade de desenvolver aulas nas escolas com os alunos, nota- 
se que a professora teve a intenção de inserir os acadêmicos em um ambiente de aprendizagem em que eles pudessem vivenciar situações de docência. Assim, eles puderam atuar como professores ao ministrar aulas para os colegas e para um grupo de alunos na escola, em um processo contínuo de (re)construir conhecimentos do tipo CTPC, conhecimentos da docência, ao longo das atividades propostas na disciplina.

A professora, ao propor atividades de prática da docência na disciplina, pareceu acreditar na (re)construção de conhecimentos, ao valorizar a autonomia dos professores em formação, ao orientar, acompanhar e oportunizar reflexões sobre as ações realizadas. Foram também movimentos contínuos de "usar o computador com seus alunos, programar novas atividades, de acordo com as necessidades levantadas, e propiciar que o formando realize a descrição, execução, reflexão e depuração do processo." (Almeida, 2000, p.114)

Ao discutir e dialogar com os professores em formação sobre as dificuldades e cenários encontrados nas escolas, podemos entender que a professora formadora da disciplina se colocava como aprendiz. Afinal, ela também aprendeu com os acadêmicos, mediando as aprendizagens, pois se constituiu um "modelo de aprendiz com profundos conhecimentos dos pressupostos teóricos que embasam os processos de construção de conhecimento e das tecnologias que podem facilitar esses processos" (Valente, 2003, p.35).

E se houve possibilidade de construção de conhecimentos, conforme analisamos neste artigo, as atividades propostas e atitude da professora da disciplina contribuíram para tal. A construção de conhecimentos, segundo Almeida (2000, p.172), "não é resultado, mas processo", e pode ter acontecido a partir do momento em que os professores em formação agiram, aceitaram a proposta, elaboraram planejamento, desenvolveram aulas, discutiram e refletiram sobre suas vivências junto com colegas, alunos na escola e professora da disciplina.

\section{Conclusão}

A partir da pesquisa realizada e da análise de "falas de egressos" que trazemos neste artigo, consideramos que as ações propostas na disciplina de Prática de Ensino, em que os professores em formação tiveram a oportunidade de praticar a docência, podem ter sido uma possibilidade de construção de conhecimentos tecnológicos e pedagógicos de conteúdo matemático (CTPC). Nessas ações, esses egressos tiveram que estudar conteúdos matemáticos e tecnologias, de maneira a atender objetivos de aulas e favorecer a aprendizagem de seus alunos.

Ao praticar a docência em sala de aula com os colegas, os professores em formação puderam aprender sobre potencialidades e limitações de software e applets para ensinar determinado conteúdo matemático. Nesse exercício da docência em uma realidade próxima à da escola, eles tiveram a oportunidade de vivenciar dificuldades que podem surgir nas aulas, e as discutir com os colegas e professora da disciplina. Já na ação realizada na escola, eles puderam vivenciar algumas situações da docência na realidade de escolas da Educação Básica, além de, nas duas ações, pensar em estratégias para envolver os alunos com as tecnologias e produzir conhecimentos matemáticos. Ou seja, ao vivenciar essas ações de docência com o uso de tecnologias, eles puderam mobilizar e (re)construir CTPC.

A partir das análises e conclusões dessa pesquisa, podemos refletir sobre a necessidade de mobilizar mais ações para a aprendizagem da docência em cursos de formação inicial de professores. Precisamos refletir sobre a importância dessa disciplina de Prática de Ensino para a aprendizagem dos acadêmicos, mesmo que isolada, em um curso de formação inicial de professores. Mas, que poderia servir de reflexão para pensar/investigar/propor processos de integração de tecnologias digitais ao currículo de cursos de formação inicial de professores, articulados com aprendizagens sobre/para a docência nas escolas de Educação Básica.

Para que tecnologias digitais sejam integradas ao currículo de uma disciplina, de um curso, um caminho é pensar em ações de formação de professores que não se limitem a estudos teóricos, mas que envolvam relações e diálogos entre teorias e práticas, oportunizando que o professor em formação vivencie/ discuta/problematize teorias ao praticá-las, e possa reconstruir teorias a partir de seu espaço de prática. Mas, sabemos que ainda há muito por agir e pesquisar nos espaços de formação inicial de professores e sua integração à cultura digital. São demandas e necessidade de pesquisas, de investimentos em formação de professores e de formadores, de investimentos em tecnologias e demais infraestruturas, de parcerias com escolas e secretarias de educação, de movimentos outros que respeitem a vida em sua complexidade...

\section{Agradecimentos}

A presente pesquisa foi realizada com apoio da Coordenação de Aperfeiçoamento de Pessoal de Nível Superior - Brasil (CAPES) - Código de Financiamento 001.

\section{Referências}

Almeida, M. E. B. (2000). Proinfo: Informática e formação de professores/ Secretaria da Educação a Distância. Brasília: MEC.

Becker, F. (2012). Educação e construção de conhecimento. 2 Ed. Porto Alegre: Penso.

Blauth, I. F. (2017). Prática de Ensino em um Curso de Licenciatura em Matemática: uma análise sobre conhecimentos tecnológicos e pedagógicos de conteúdo. Dissertação (Mestrado em Educação Matemática). Universidade Federal de Mato Grosso do Sul.

Carneiro, R.F. (2008). Da licenciatura ao início da docência: vivências de professores de Matemática na utilização de tecnologias da informação e comunicação. Dissertação (Mestrado em Educação). Universidade Federal de São Carlos.

Gatti, B. A. (2013/2014). A formação inicial de professores para a educação básica: as licenciaturas. Revista USP, (100), p.3346.

Koehler, M. J.; Mishra, P.; Akcaoglu, M. \& Rosenberg, J. M. 
(2013). The Technological Pedagogical Content Knowledge Framework for Teachers and Teacher Educators. Disponivel em: $\quad$ http://cemca.org.in/ckfinder/userfiles/files/ICT\%20 teacher\%20education \%20Module\%201\%20Final_May\%20 20.pdf.

Koehler, M.J., \& Mishra, P. (2005). What happens when teachers design educational technology? The development of Technological Pedagogical Content Knowledge. Journal of Educational Computing Research, 32(2), p.131-152. doi: 10.2190/0EW7-01WB-BKHL-QDYV.

Marcon, D.; Graça, A.B.S. \& Nascimento, J.V. (2010). Reflexões sobre o processo de construção do conhecimento pedagógico do conteúdo de futuros professores. In: Anais V CINFECongresso Internacional de Filosofia e Educação. p.1-17.

Mishra, P. \& Koehler, M. J. (2006). Technological Pedagogical Content Knowledge: A Framework for Teacher Knowledge. Teachers College Record, 108(6), p.1017-1054. doi:10.1111 j.1467-9620.2006.00684.

Nogueira, C.M.I. (2013). A formação de professores que ensinam matemática e os conteúdos escolares: uma reflexão sustentada na epistemologia genética. Revista Eletrônica de Psicologia e Epistemologia Genéticas, 5.

Orlando, J.\& Attard, C. (2016). Digital natives come of age: the reality of today's early career teachers using mobile devices to teach mathematics. Mathematics Education Research Journal, 28, p. 107-121. doi: https://doi.org/10.1007/ s13394-015-0159-6

Prenski, M. (2001). Nativos digitais, imigrantes digitais. Disponivel em: http://www.colegiongeracao.com.br/ novageracao/2_intencoes/nativos.pdf.

Shulman, L. (1986). Those Who Understand: Knowledge Growth in Teaching, Educational Researcher, 15(2).

Valente, J. A. (2003). Formação de educadores para o uso da informática na escola. Campinas: UNICAMP/NIED.

Valente, J. A. (2005). O ciclo de ações e a espiral da aprendizagem. In: Valente, J. A. A espiral da espiral da aprendizagem: o processo de compreensão do papel das tecnologias de informação e comunicação na educação. Campinas: Universidade Estadual de Campinas. 